PROFESSIONAL MILITARY COMPTROLLER SCHOOL

\title{
IDEA PAPER
}

\section{TITLE \\ Give the MAJCOMs the Ability to Directly Input Into the F\&FP Database}

\author{
AUTHOR
}

William H. Renica III

GS-12, USAF

Class
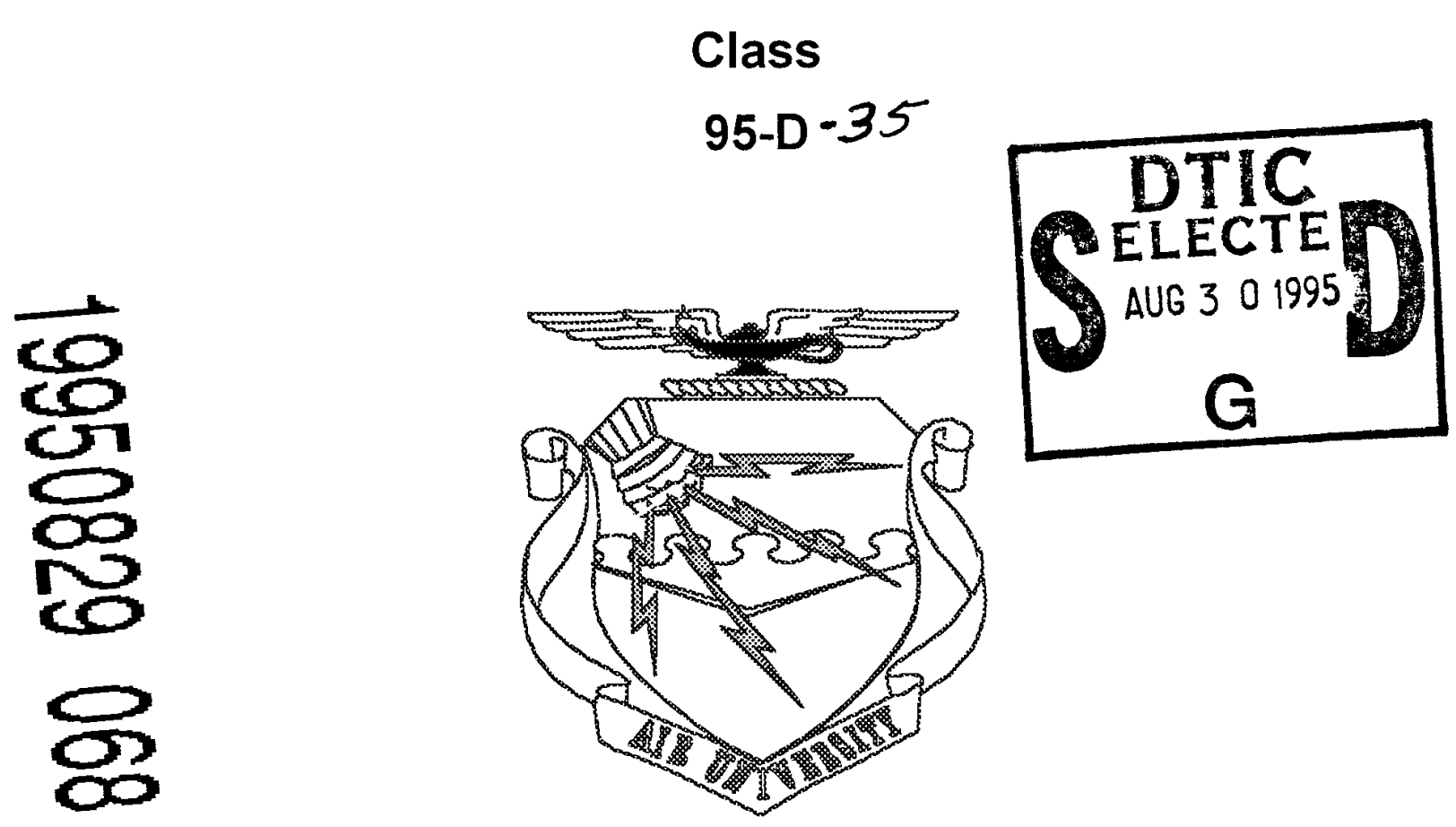

DTIE QUATITY INSPECTED 8

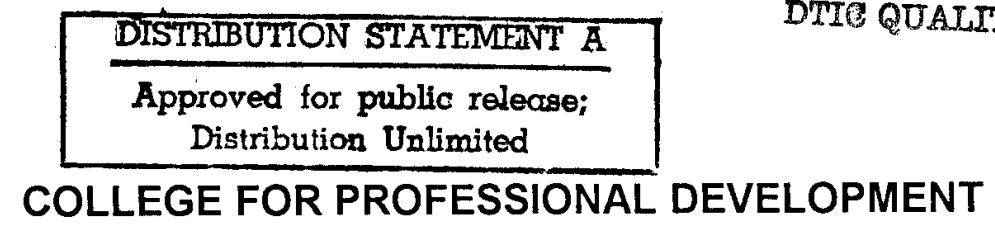

AIR UNIVERSITY/UNITED STATES AIR FORCE/MAXWELL AFB, ALABAMA 


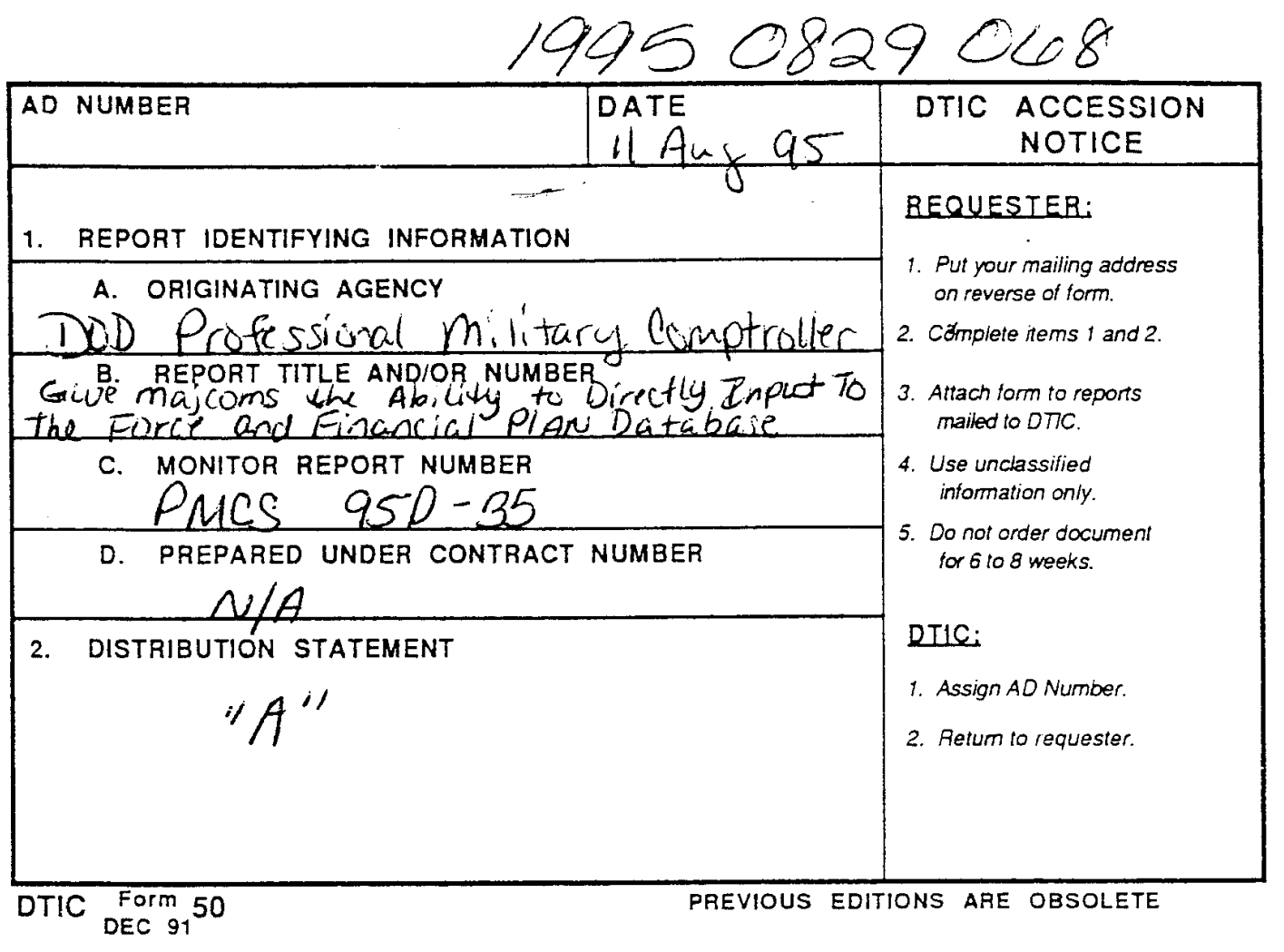




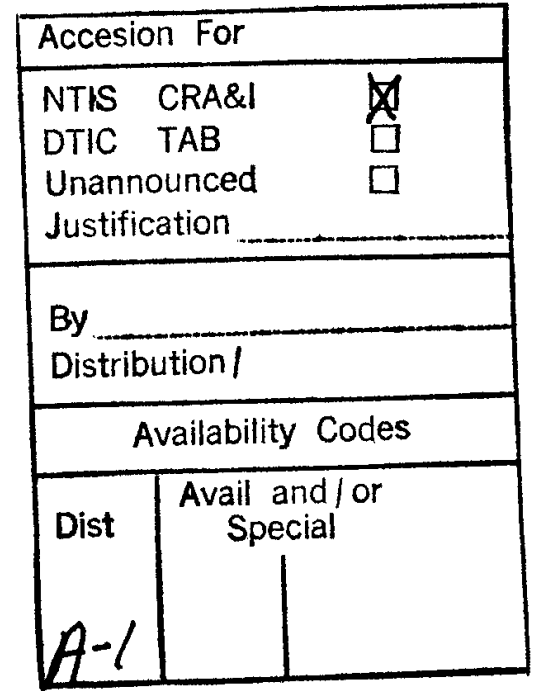

This study represents the views of the author and does not necessarily reflect the official opinion of the College for Professional Development, Air University, or the Department of the Air Force. 


\section{PMCS IDEA PAPER}

TITLE: Give the MAJCOMs the Ability to Directly Input Into the F\&FP Database PMCS CLASS: 95-D

AUTHOR: William H. Renica III RANK: GS-12 SERVICE: USAF

DUTY ADDRESS: HQ ACC/INFP

DSN: $574-7734$

129 Andrews Street STE 150

Langley AFB VA 23665

\section{EXECUTIVE SUMMARY}

The F\&FP database is not a good reference for how the MAJCOMs plan to execute their budgets. The underlying problem is that it is difficult to for the MAJCOMs to align the F\&FP database with their Financial Plan. However, by changing the current procedures with a new database program the Air Staff can give the MAJCOMs the ability to directly input into the database. This new program can save man-hours for the Air Staff by forcing the MAJCOMs to input information in the F\&FP database. Also, the information will more accurate and timely the F\&FP database is a better basis for decisions. This paper outlines a simple program to be implemented over a short period of time and preserve the integrity of the F\&FP database at a relatively low cost. 


\section{Table of Contents}

Introduction
Background .
Discussion
Purpose
Integrity
Connectivity
Procedures
Recommendation


Introduction

It's a Tuesday afternoon in November at Langley AFB and as you look out the window and watch the leaves blow in the wind your phone rings. You pick up the phone wondering who is calling you before Thanksgiving. Much to your surprise it is the Air Force Program Element Monitor (PEM) for your program. As the Air Combat Command (PEM) you have completely memorized your program and know where every dollar is and what projects it supports. The Air Force PEM informs you that your program has $\$ 550 \mathrm{~K}$ for Automated Data Processing Equipment (ADPE) costs for every year in the database. The Air Staff wants to know why your program decreased by $\$ 750 \mathrm{~K}$. Unfortunately for you the Air Force PEM is new and is not familiar with the program. As you hang up the phone you wonder what happened to your program, according to the last report you had 1,300K for ADPE. Anybody involved in the Planning, Programming and Budgeting System (PPBS) have had their program numbers change without notification. Therefore it is essential that the Air Force MAJCOMs can directly modify the Force \& Financial Plan (F\&FP) database.

\section{Background}

The ultimate objective of the DoD PPBS is to provide the best mix of forces, equipment, and support attainable within fiscal constraints $(1,1)$. The process begins with unified/specified CINCs, their Air Force components, and Air Force commanders assessing potential threats against national interests and objectives, translating guidance from the President and the Secretary of Defense into operational plans, and identifying the resources needed to execute their plans $(2,1)$. The PPBS goes through various cycles within the biannual process. Through out these exercises the starting point is the previous cycle. Consequently, the Air Force MAJCOMs need 
the ability to directly input and modify data in the F\&FP database. This capability will improve the accuracy of information. At Air Combat Command (ACC) an automated electronic interface that preserves the classification of the F\&FP database can be easily implemented.

\section{Discussion}

One example where this has been implemented is by the SC community in developing the Technology report for Congress. This report is a series of exhibits compiled by the Air Staff from each MAJCOM into the Air Force P43 exhibits. The first step, the Air Staff queries the F\&FP database for all ADPE Element Expense Investment Codes (EEIC) to construct a separate database from the F\&FP. This database is then used as a starting point for P43 exhibits. The Air Staff then sends detailed instructions to the MAJCOMs with suspenses for the tasks involved to build the exhibits. Each MAJCOM's representative can call and log onto the system to look at their ADPE programs to process data to complete the assigned tasks. The program allows each representative to make Zero Based Transfers within each PEC. Personnel also fill out various reports and provide the necessary information to complete the exhibits. The Air Staff reviews all changes before any permanent alterations to the F\&FP database. This preserves the integrity of the database, but allows the MAJCOMs to have input into the system and provide the personnel for the data entry work.

\section{Purpose}

Why should the MAJCOMs and the Air Staff want to do this project and how can it be done at a low cost? This paper will answer that question and provide a solution at a reasonable cost by using ACC as a model. The first and most important purpose are the F\&FP database will have more accurate and timely information than previously. It will permit direct electronic 
exchange of data for exercises and what if drills. Also, any reductions or increases that use to be applied across the board can now be directly applied by the MAJCOM and still reflect their execution strategy. This maintains the usefulness of the information in the F\&FP database. Another benefit is the elimination of printing data from one system and then typing the data into another computer. The underlying goal is to improve the accuracy of data and reduce the workload on the Air Staff. To accomplish this goal the MAJCOMs can do the data entry work for the Air Staff. The first step is to make a dummy database that replicates the original F\&FP database. This preserves the integrity of the original database. The next step is to provide connectivity to the Air Staff through STU-IIIs or any existing leased long line for connectivity. The third and final step are to build the procedures and formats for processing changes.

\section{Integrity}

The first step is to replicate the F\&FP database. Not being familiar with the operations of the ABIDES system or the computer system it resides on, I will make several assumptions that will have a minimal impact on implementing this idea. First, the F\&FP database for the Air Force is no greater than $9 \mathrm{M}$ bytes. ACC's portion of the F\&FP database is $2.5 \mathrm{M}$ bytes. Second, the various databases that may reside in the system at one time and the need to back up data should never exceed $200 \mathrm{M}$ bytes. By current standards this is a small amount of hard drive space. If the Air Staff does need to procure additional hard drive capacity this expense should not exceed $\$ 1 \mathrm{~K}$. For example 1.2 Giga bytes hard drive cost $\$ 800.00$, which is five times the amount of space required for this program. Third, the ABIDES system can import and export data as an ASCII file. Therefore the program should be in a language that can import and export ASCII files. Also, since the MAJCOMs will be processing the work on personal computers, then the language needs to work on both the Air Staff 's computer and personal computers. There are several languages 
that can meet the necessary requirements. One choice is Foxpro by Microsoft Corporation. This language can easily import and export ASCII files. It can operate in DOS, Windows, or UNIX operating environments. This language can operate lower level programming functions such as controlling a modem. Additional benefits are that Foxpro can generate detailed menus to simplify operation of a program. One example is Mobil Corporation that uses a series of personal computers and Foxpro to control their ships around the world through various communication channels. This system provides real time information on the location of ships, their cargo and other information.

\section{Connectivity}

The next step is to establish connectivity. Again there are several options for this system. One option would be to employ a dedicated leased long line. This provides a high throughput with very good response time. Since cost is an important consideration, it may be too expensive to provide a dedicated leased long line between Langley AFB and the Pentagon just to support the PPBS for ACC. Therefore, ACC and the Air Staff need to explore the possibility of piggy backing onto another system. One such system is the Joint Worldwide Intelligence Communications System (JWICS). However, due to security regulations this may not be sensible. Another system is the Global Command and Control System (GCCS). However, the most plausible and cheapest solution is to use STU-IIIs for their MODEM and encryption capability. A STU-III with a 9600 BAUD MODEM can be bought for under $\$ 1.5 \mathrm{~K}$. An example of a system that is currently using a similar setup is the Digital Image Transmission System (DITS). This is a secondary imagery transmission system that uses STU-IIIs to pass classified imagery.

\section{Procedures}


The last step is to design procedures and build the formats for the system. The formats should remain the same as before but translated into an electronic format. The new procedures should include a new method for creating a new Change Control Number (CCN). This system needed to track changes from the MAJCOMs to the Air Staff. ACC would use the CCN index to build a database of changes and realignments. These changes would be a result of taskings, implementation of new strategies, or realignment of execution strategy. The changes can be sent back to the Air Staff as an electronic database. This database can then be converted back into an ASCII file and put back into the system to be reviewed for approval by the Power Teams. Approval for Zero Based Transfers (ZBT) within a PEC can be delegated to the Air Force PEM. Once a change is approved then the changes can be added to the database with a push of a button. ACC can use the Air Staff electronic formats and follow its procedures to build its database of changes and realignments.

\section{Conclusion}

In conclusion the Air Force can implement a system that allows the MAJCOMs a direct electronic input into the F\&FP for the PPBS. In order for the PPBS to work properly there needs to be a strong relationship between the Air Force PEM and his/her counterparts at the MAJCOMs. The Air Staff PEM has the big picture and is driving the program toward that goal. However, the actual execution belongs to the MAJCOM PEM and his/her budget personnel. Therefore, the MAJCOMs can align the programs with there intended execution plan to provide the Air Staff with more accurate information. Also, any MAJCOM can easily tie their piece of the F\&FP with previous obligations to analyze their programs for performance. The first step is to design the procedures and formats. The next step is to analyze the requirements to implement the procedures and formats into an Xbase language. There are two choices for the Air Staff for 
designing and building the software program. One is to contract for the programming to a private firm. The cost can be kept at a $\$ 50 \mathrm{~K}$ to $\$ 75 \mathrm{~K}$ range as long as the bells and whistles are kept to a minimum. The other option is to use personnel at the Standard Systems Group (SSG) to design and build the program. SSG has already designed and developed an Xbase program for FM called Microbas. The Microbas program is a good example of an Xbase language (Clipper) to give MAJCOM personnel an electronic capability for various reports. The last step is to provide the connectivity between the MAJCOMs and Air Staff. The cheapest and easiest solution is to use STU-IIIs to transfer information over existing phone lines. These phones cost less than $\$ 2 \mathrm{~K}$ and come with a 9600 baud modem. Also, a variation of the STU-III is available that only transfers data at 14,400 baud. By incorporating the STU-III modem parameters into the Xbase program the user can operate the system from their computer without having to program the modem.

\section{Recommendation}

The Air Staff should task SSG at Gunter Annex in conjunction with the 7 CCGP at the Pentagon to design and build a program to give the MAJCOMs the capability to electronically interface with the ABIDES system. This system can be completed at a cost of $\$ 100 \mathrm{~K}$ to $\$ 200 \mathrm{~K}$ over a period of two years. This capability will improve the accuracy of information in the F\&FP database by allowing the MAJCOMs to directly input data. 
Bibliography

1. DoD Directive 7045.14

2. The Planning, Programming and Budgeting System Primer, May 1993, page 1 